\title{
Gender Differences in Early Retirement Behaviour*
}

\section{Svenn-Åge Dahl ${ }^{\mathrm{a}}, \varnothing_{\text {ivind Anti Nilsen }}^{\mathrm{b}}$, and Kjell Vaage ${ }^{\mathrm{b}}$}

January 2002

\begin{abstract}
In this paper we analyse early retirement for men and women focusing on family characteristics such as marital status, spouse income and wealth, and spouses' labour market status. The female participation rate is high in Norway, implying that the country is particularly suitable for the study of gender differences in the early retirement behaviour. At our disposal we have administrative data that include information on individuals aged between 55 and 61 years in 1989. The individuals are followed until the end of 1995, with the aim of determining the predictors of different early retirement states. The results of a competing risk model indicate that women are less likely to take early retirement compared to men and that these differences are due to both different characteristics and different behaviour.
\end{abstract}

Keywords: Early retirement, gender differences, labour force participation.

* Financial support from the Research Council of Norway (The Programme on Welfare Research) is gratefully acknowledged. The data for this analysis were provided by the Norwegian Social Science Data Services (NSD). NSD is not responsible for the authors' analyses. We have also benefited from useful and constructive comments of seminar participants on several occasions. The usual disclaimer applies.

${ }^{a}$ Foundation for Research in Economics and Business Administration (SNF), Breiviksveien 40, NO-5045 Bergen, NORWAY. Tel. + 47559595 04, Fax. + 47559594 39, E-mail: SvennAage.Dahl@snf.no.

${ }^{\mathrm{b}}$ Department of Economics, University of Bergen, Fosswinckelsgate 6, NO-5007 Bergen, NORWAY.

Tel. +4755 5892 00, Fax. +47 555892 10, E-mail: Oivind.Nilsen@econ.uib.no, Kjell.Vaage@econ.uib.no. 


\section{Introduction}

The age at which people retire from the labour market has been drifting downwards in most OECD countries. More than a quarter of the OECD countries have an average retirement age below 60 for males, and more than half of the countries have an average age of retirement below 60 females (Blöndal and Scarpetta, 1998). The number of years in employment for men is decreasing, and retirement now begins so early that they spend only half their life in work (The Economist, 1999). At the same time fertility is reduced, the health of older people has improved in several countries and people live longer. Fifty years ago, European men and women worked seven years longer than they do now - and lived 11 years shorter. The proportion of elderly in the population is therefore increasing and will continue to grow in the years to come. The decline in the labour force participation of older persons is described by Gruber and Wise (1998: 158) as: “. . . the most dramatic feature of labor force change over the past several decades". As a consequence, early retirement causes great concern for the financing of the welfare states in the immediate future. Thus, early retirement is an important topic on the political agenda in most countries, and has already led to changes in the pension systems and rise in the official retirement age in countries like USA, Greece, Italy, New Zealand, Japan and, recently, Germany.

In this article, we study the use of various early retirement pathways for men and women, where pathways refer to different institutional arrangements that are sequentially linked to manage the transition from work into old-age retirement (Kohli and Rein, 1991). Gender differences in the exit probability may be due to differences in the background characteristics, and/or to various responses to changes in these characteristics. For each individual we have detailed information on age, education, income, etc. In addition, we pay particular attention to family characteristics such as 
marital status, spouse income and wealth, and spouses' labour market status. For married individuals there are several sources of joint retirement behaviour, "added-worker" vs. "assortative mating" effects, and/or correlation in unobserved tastes. ${ }^{1}$ Among the older cohorts, men generally have higher education and normally better paid jobs than women. We also know that women generally marry men with higher social status than themselves. Furthermore, men are often the breadwinners of the family. These are examples of issues that may induce gender differences in the use of various retirement pathways. Thus, it is crucial not to restrict the retirement paths of the two genders to being identical. The contribution of this paper is a comparison of male and female retirement behaviour.

Previous research on female retirement behaviour, as compared to male, is limited mainly because of lack of data. The labour force participation rates for elderly are high in Norway compared to most other OECD countries. In particular this is evident for older females. The labour force participation for Norwegian women aged 55-66 years has increased from $40.1 \%$ in 1972 to $54.1 \%$ in 1997 . The labour force participation for men in this age group, on the other hand, has in the same period been reduced from $81.0 \%$ to $68.8 \%$. The average retirement age is falling, and for new pensioners it is now 59 years while the standard age of entitlement to public old-age pension is 67 years. As for most of the OECD countries, the proportion of elderly is rising also in Norway, and this trend will continue in the next few decades. Given the significant participation rates for older females, Norwegian data may be particularly suitable for the analysis of joint exit from the labour force. We have utilised the very rich KIRUT database; a database that contains detailed individual information for a random $10 \%$ sample of the Norwegian population aged 16-67. We have collected data on more than 10,000 individuals aged 55-61 years in 1989. These individuals are followed until they transit from work or until the end of 1995. In our analysis we use a discrete choice model with 
several destinations or pathways: disability pension, unemployment benefits, and out of the labour force. Both the disability and unemployment insurance have functioned as informal early retirement pensions in Norway, while no fully public early retirement scheme exits.

The remainder of the paper is organised as follows. In Section 2 we briefly review the relevant literature on retirement and position ourselves relative to the various perspectives. In Section 3, we describe institutional features of the Norwegian retirement system. Section 4 gives a description of the sample together with modelling and explanatory variables. In Section 5, we comment on the development in the probabilities of ending up in various end-states. In the same section, we give the descriptive statistics and the empirical results. The last section, Section 6, provideses a more general discussion of the gender differences in early retirement and what policy implication these might have.

\section{Lessons from the Retirement Literature}

Research on the labour market shows that there are gender differences in several important areas.

Differences are found for example in hourly/weekly wages and annual earnings, labour force participation, occupational attainment and the likelihood of receiving a pension. Women's wages and earnings are lower than men's and so are their labour force participation rates, as well as their likelihood of receiving a pension and getting promotion (e.g. Even and Macpherson, 1990, 1994; Altonji and Blank, 1999; Spilerman and Petersen, 1999). The differences have been persistent over time although the nature and magnitude of differences have changed as men's and women's work histories are becoming more similar (Hayward, Hardy, and Grady, 1989; Altonji and Blank, 1999). 
Despite the important gender differences, most of the research on early retirement decisionmaking is studies of men (e.g. Haveman, Wolfe, and Warlick, 1988; Berkovec and Stern, 1991; Blau, 1994; Meghir and Whitehouse, 1997; Riphahn, 1997). ${ }^{2}$ The analyses of gender differences in early retirement are more limited. Talaga and Beehr (1995) study gender differences in retirement decisions in a large Midwestern manufacturing organisation (US). Their results show that the retirement decisions differed between men and women primarily when dependants lived in the household, when the health of one's spouse was a consideration, and when one's spouse was retired. $^{3}$ A great number of studies document that husbands and wives co-ordinate work and retirement decisions, but there is no clear evidence as to who is leading who. Since women typically marry older men, co-ordination of retirement implies that wives are likely to retire at a younger age than their husbands (Ruhm, 1996). Henretta, O'Rand, and Chan (1993) find that a woman's employment during childbearing years is associated with earlier retirement, especially following her husband's retirement. ${ }^{4}$ Other studies have found that the presence of children in the family has only small effects for women, while it significantly reduces the probability of leaving the labour force for men (Perrachi and Welch, 1994; see also Reitzes, Mutran, and Fernandez, 1998).

Differences between married and unmarried men and women in their retirement behaviour are also found for example by Perrachi and Welch (1994). Men who are not married have a higher probability of leaving the labour force and a lower probability of exiting retirement. On the other hand, women who are not married have a significantly lower probability of leaving the labour force, and a higher probability of exiting retirement. Ruhm (1996) finds that unmarried men and women with work experience after the age of 50 have identical probabilities of working or holding full time jobs. Marriage, on the other hand, is associated with elevated labour supply for men and reduced employment for women. Yabiku's (2000) analyses indicate that family history has opposite effects 
for men and women. Compared to men that stay married, single and divorced men have lower odds of private pension receipt, while having a child is associated with higher odds. For women, being single or divorced is associated with higher odds of pension receipt, and having children decreases their odds.

There has also been some research on the labour market effects of care-giving responsibilities. It is found that more women than men retire for care-giving reasons (Matthews and Brown, 1987; Richardson, 1993), and women consider their family situations more often than do men when it comes to situations concerning retirement (O'Rand, Henretta, and Krecker, 1992; Ruhm, 1996; Szinovacz and Ekerdt, 1995). Hatch and Thompson (1992) find that having an ill or disabled household member who requires assistance is the greatest predictor of retirement among women. Ruhm (1996) finds that substantial care-giving (more than 10 hours a week) is associated with reduced job holding among married persons, but with increased employment for single persons.

There are some studies of early retirement using data from the Nordic countries, and several of these are found in Wadensjö (1996). Pedersen and Smith (1996), using a competing-risk model with three different end-states, find that there are significant gender differences in the decision to retire early in Denmark. These results may be contrasted with those of Lilja (1996), based on Finnish data and using a competing-risk model with four destination states, who finds that the propensity for early exits does not differ significantly between males and females. Her study also shows that the presence of a retired spouse at home encourages the other spouse to consider early retirement. Furthermore, women are less likely than men to take early retirement or to retire due to unemployment, and more likely to exit without an immediate pension.

As already pointed out, using Norwegian data to investigate the early retirement process is of great interest since the female participation rate is rather high in Norway. To our knowledge there 
are only a few microeconometric analyses based on Norwegian data. Two of these are primarily studies of the privately negotiated early retirement scheme - (“AFP”). Hernæs, Sollie, and Strøm's (2000) prime motivation is to model the likely effects of changing the eligibility criteria of the AFPscheme. In this study, gender differences are restricted to a gender dummy only. This is also the case in the study by Bratberg, Holmås and Thøgersen (2000). They use a competing risk framework and find that AFP to some degree relieves the pressure on disability pension and unemployment benefits. The gender difference in early retirement is given more attention in Dahl, Nilsen and Vaage (2000). However, they do not utilise their data fully satisfactorily. They have annual data, but in general only use information at the beginning and the end of the seven year time interval. In our study, the data used by Dahl, Nilsen and Vaage (2000) are extended somewhat and, more importantly, the fact that the data contain yearly information is utilised.

Our study differs from most of the studies cited above in the following respects. First, our study pays special attention to female retirement and gender differences in the retirement decision. Second, our data make it possible to distinguish between different pathways, which is important to capture the forces behind the choice of various pathways. This is especially important since both the behaviour and the characteristics of men and women may induce variation in the preference for or choice of various pathways. Third, our data include a broad range of information on family characteristics, which in our opinion are important both for the study of gender differences and the choice of pathways, and largely neglected in the retirement literature. Neglecting family characteristics leads to a major loss of fit in the case of women, especially in the case of exit from full-time work (Peracchi and Welch 1994). 


\section{Institutional Background}

The various pathways out of work in Norway are illustrated in Figure 1. The standard retirement age in Norway is 67 years on the condition that a person gives up the right to keep a specific job. However, some professions and occupations have a lower pension age and some are fixed by law. ${ }^{5}$ The compulsory retirement age is 70 .

(Figure 1 about here)

As in several other countries, institutional arrangements that were originally constructed for other purposes, notably unemployment benefits and disability pension, have been used as pathways to early retirement. Until the early 1990s the entitlement conditions for disability pension in Norway were liberal, and labour market conditions were a factor in the disability assessment. Before receiving disability pension, sickness insurance is usually paid for one year, and a subsequent period in a rehabilitation program is required. To qualify for a disability pension, a person must demonstrate that his/her ability to earn an income has been permanently reduced by at least $50 \%$.

Older people are entitled to unemployment insurance for an extended period. Persons who become unemployed when they are 60.5 years or older can receive unemployment insurance until they reach the standard retirement age of 67 years.

There are several early retirement pathways with private provisions in Norway, even though the use of these is in general not very common. The most important non-public early retirement 
scheme in Norway is AFP ("Early Retirement Pension Agreement - AFP”). This scheme came into effect as from 1 January $1989 .{ }^{6}$ The use of the scheme has increased as the retirement age has been reduced (62 as of 1 March 1998), as the replacement rate has been improved (in 1992) and as knowledge of the scheme has imcreased. The AFP scheme is supported financially by the state (40\%), and represents entitlement for those with at least ten years of social security contributions, and for those whose pension income is at or above a certain minimum. The pension is the same as the full pension entitlement, but is less favourably treated under income taxation than a full old-age pension.

In contrast to many other countries, partial retirement and bridge jobs play a minor role in the transition from work to retirement in Norway, and are not as important as they are, for example, in the United States (Ruhm, 1990; Quinn and Kozy, 1996).

The replacement rate is different for the various types of retirement schemes, and this may give different economic incentives conditional on the retirement pathway that is used. ${ }^{7}$ The replacement rate varies between 60 and $90 \%$ for the private/non-public retirement schemes. The replacement rate for disability pension is about $62 \%$, but in order to increase the employees' incentives to apply, employers in many firms pay a small company pension in addition to the state paid disability pension, thereby increasing the replacement rate up to $80 \%$. The standard replacement rate for unemployment is $63 \%$. Also for this retirement scheme, several firms pay a small company pension to employees who agree to be "voluntarily" laid off, which increases the replacement rate substantially. The replacement rate for AFP varies between 50 and $60 \%$. Moreover, a new trend is that some firms pay a company pension to former employees in addition to the AFP pension. 


\section{Data and Modelling}

\section{Sample Construction and Early Retirement States}

The analysis is based on data from the KIRUT database. ${ }^{8}$ The base contains detailed individual information on socio-economic background, labour market participation, and social insurance payments for a random 10\% sample of the Norwegian population aged 16-67 (the total sample exceeds 300,000 individuals).

Our sample includes observations of individuals born between 1929 and 1934 who occupied a job on 1 January $1989 .{ }^{9}$ Initially we utilised only observations for the individuals for which we have, for our study, all the relevant information in all the years from 1989 until 1995. After excluding individuals with missing variables during the sample period, we end up with a balanced sample of 10,315 individuals, 5,383 males and 4,932 females. The sampled individuals were followed until they transited into either disability, unemployment, or out of work. All the observations from 1989 until the year of transition are pooled. Thus if an individual experienced a transition in, for example, 1993, he/she is represented with five observations. If they do not experience a transit before 1995, we follow them every year until 1995. The pooled sample consists of 29,162 observations of men, and 26,946 observations of women.

All individuals in the final sample were classified into one of four groups, disability, unemployment, out of work, or working, based on their labour market status in 1995. By construction, we are working with absorbing states. In this way, we avoided the problems of round tripping, i.e. individuals moving in and out of the different states in the interim period. As pointed out in Figure 1, Section 3, individuals that become disabled go through a period with sickness insurance and a subsequent rehabilitation program. We therefore classify the disabled as disabled from the 
beginning of the sickness period, given that the individuals were more than $50 \%$ disabled as at 31 December $1995 .^{10}$ The second end-state is unemployment. We are only interested in individuals with long-term unemployment, who stay unemployed throughout our period of observation. Thus, we ignored unemployment spells shorter than 6 months. Consequently, the unemployed was defined as those who were registered as job seekers as at 31 December 1995 and whose unemployment spell started before July 1995. Note that we let disability "overrule" both unemployment and employment. For instance, an individual with an unemployment spell starting before a period of disability is classified as disabled. Hence, this individual's transition from work to disability was at the starting point of the disability spell. ${ }^{11}$ Finally, individuals who were not registered as either worker, disabled or unemployed were defined as out of work. The latter group includes individuals who have retired due to private or firm-provided early retirement schemes, and individuals who have dropped out of the labour force for other reasons, i.e. those who have ended their job without being entitled to any public or private pensions. As a consequence, this is a rather heterogeneous group, and care should be taken when interpreting the empirical results for these individuals. ${ }^{12}$ The point of transition for the individuals in the out of work group is the last day in the employers' register.

\section{Modelling}

The objective of this study is to test empirically how males and females respond differently to variations in relevant characteristics and variables. More specifically, we ask the question, what factors affect the probability of being observed in different end-states in a given year $t$, conditional on being in the state of work in the previous year, $t$-1? As pointed out by several authors, individuals are either pushed into or choose different early retirement pathways (see for instance 
Boskin and Hurd, 1978; Haveman, Wolfe and Warlick, 1988; Kohli and Rein, 1991; Riphahn, 1997). The underlying hypothesis is that the determinants of the transitions from work into different states are identical, even though the importance of these determinants is different for each of the various transitions.

Formally, we assume that individual $i$ chooses alternative $j$ at time $t$ if the associated utility, $U_{i j t}$, is the highest of all $J$ alternatives. For each individual we define a latent variable, $Y_{i j t}^{*}$, which denotes the change in utility of moving from the state work in year $t-1$ to early retirement in year $t$. The (change in) utility is determined by a vector of observable variables, $\mathbf{x}_{i t}$, including expected income in the different states, personal characteristics, labour market conditions, etc., and a stochastic error term, $\varepsilon_{i j t}$ :

$$
Y_{i j t}^{*}=U_{i j t}-U_{i, w o r k, t-1}=\mathbf{b}_{j}^{\prime} \mathbf{x}_{i t}+\varepsilon_{i j t} \text { with } j=0,1,2,3 \quad t=1989 . . T_{i}
$$

where $T_{i}$ is the year individual $i$ is exiting work. What we observe, however, are the discrete choices,

$$
Y_{i j t}=\left\{\begin{array}{l}
1 \text { if } Y_{i j t}^{*}>0 \\
0 \text { if } Y_{i j t}^{*} \leq 0
\end{array}\right.
$$

Thus, the probability of choosing state $j$ can be expressed as:

$$
\operatorname{Prob}\left(Y_{i j t}=1\right)=\operatorname{Prob}\left(Y_{i j t}^{*}>0\right)=\operatorname{Prob}\left(\varepsilon_{i j t}>-\mathbf{b}_{j}^{\prime} \mathbf{x}_{i t}\right) .
$$


We assume that $\varepsilon_{i j t}$ is type I extreme-value and independently and identically distributed across alternatives and individuals. The estimations can then be implemented through the multinomial logit model:

$$
\operatorname{Prob}\left(Y_{i t}=j\right)=\frac{e^{\mathbf{b}_{j}{ }^{\prime} \mathbf{x}_{i t}}}{\sum_{j=0}^{3} e^{\mathbf{b}_{j}{ }^{\prime} \mathbf{x}_{i t}}}
$$

In Section 5 we focus on competing risks, and report the marginal effects found by differentiating equation (3):

$$
\frac{\partial P_{j i}}{\partial \mathbf{x}_{\mathbf{i}}}=P_{j i}\left[\mathbf{b}_{\mathbf{j}}-\sum_{k=0}^{3} P_{k i} \mathbf{b}_{\mathbf{k}}\right]
$$

where $P_{i j t}$ equals $\operatorname{Prob}\left(Y_{i t}=j\right)$ as defined in equation (3). We allow all the covariates to have various impacts on the flow to different states for the two genders by carrying out the analysis separately for males and females.

\section{Explanatory Variables}

KIRUT allows us to control for a broad range of individual characteristics. Marital status is defined as married, unmarried, widow (or widower), or divorced. We include a dummy if the individual has dependent children ( 1 if children are under age 18 , and 0 otherwise). In addition to each person's age we measure any potential effect of the age difference between spouses. As 
measures on human capital we have access to educational level, measured in number of years, and experience, measured as number of years with earnings above $1 \mathrm{G} .{ }^{13}$ Being a civil servant may also be of importance for the choice of retirement pathways, due to significant job protection in the governmental sector.

Income in different states will give incentives to choose between different states since the financial reward of each state is different. Implicitly we assume that the individuals choose among expected income streams in different states. We have incorporated three different income variables in our analysis. Of course, we can only observe the income in the actual state. However, by using the relevant rules for the benefits and pensions in different states, we are able to construct potential incomes in the end-states. All the various income variables are based on the income previous to the retirement year. Income as employed is equal to the income when an individual was working. Income as unemployed in Norway is $62.4 \%$ of income the previous year up to approximately NOK 240,000 (in 1990 prices). For income higher than NOK 240,000, unemployment benefits are constant. The last income variable, income as disabled, is based on age and pension points earned. Income as disabled is approximately $62 \%$ of work income. ${ }^{14}$ We have also included both own wealth and spouse wealth. Spouse income is also included together with a dummy variable indicating whether the spouse is eligible for old-age pension, or whether s/he receives rehabilitation and/or disability pensions $(1=$ old-age pensioner or benefit receiver $)$. By including these two variables, together with the spouse wealth, we intend to test whether the "added worker" effect or "assortative mating" is present. All income variables (income as employed, unemployed and as disabled, and spouse income) and wealth (own and spouse wealth) are measured in NOK 10,000 (1990 prices). ${ }^{15}$ 
The overall tendency of utilising different forms of early retirement may vary over the business cycle, either due to push or pull factors. Moreover, the timing and magnitude of business cycles may vary between industries. Thus, we have included year dummies and six industry dummies in our empirical model. We have also included some characteristics of the local municipality in which an individual resides. Residence density measures the share of the population in a local municipality that lives in urban areas $(0-9$ (dense)). Distance to centre is a categorical variable that takes account of distance to larger central areas or cities (categories 1-7 (close)). The unemployment ratio is the ratio between unemployed and unemployed plus employed in the local municipality.

\section{Empirical Results}

\section{The Probabilities of Ending in Various End States}

In Table 1, we have calculated the probabilities of transition to different states for each gender, conditional that the individuals were working at the end of the previous year.

(Table 1 about here)

Ignoring the gender differences for a moment, we see that the probabilities of staying employed are decreasing over time. At the same time, the probability of ending in the states disabled or unemployed, together with out of work is increasing over time. The driving force behind this tendency is, of course, the fact that the individuals in our sample are getting older over time. Note also that there seemed to be a relative large increase in the probability of ending up as 
out of work in 1994 and 1995. This is evident for both genders and may be due to reductions in the retirement age in AFP from 66 years in 1989 to 64 in 1993 (October 1). ${ }^{16}$ Moreover, for those who had access to AFP, the tendency to utilise it increased in this period. Aggregate numbers state that AFP is more common in the public sector than in the private sector and that the propensity to use AFP is higher for men than for women.

Turning to the gender differences, there seems to be a tendency that females are more likely to end up as disabled, rather than as unemployed, while the opposite is true for males. We also see that there is a slight tendency for women to retire later than men (i.e. they are working longer). Even though care should be taken with regard to the out of work group since it is rather heterogeneous, we see in Table 1 that males are slightly more likely to use this pathway than females. The aggregate number of men and women in various end states is shown in Figure 2.

(Figure 2 about here)

The descriptive statistics of the explanatory variables are given in Table 2.

(Table 2 about here)

A brief look at the gender differences tells us that females are more likely to be married. We expect individuals with high human capital investment to be less inclined to early exit from the labour force. We have access to information on education, measured in number of years of highest grade completed, and experience, measured as the number of years with earnings above the eligibility level for old age pension. ${ }^{17}$ The human capital variables are also as expected with men having more years 
of education and more work experience. We also see that males (females) have a relatively high (low) own income, while their spouses have lower (higher) income and wealth.

(Table 2 about here.)

\section{Multinomial Logit Model Results}

The results from the multinomial logit model, reported as marginal effects, are given in Tables 3 and 4 (males and females, respectively).

(Tables 3 and 4 about here.)

The first three variables compare the effects of being single (unmarried, widow(er), or divorced) to that of being married. Overall, there is a tendency of increased probability of early retirement for males, even if divorcés' exit to unemployment is the only effect that is significant at the $5 \%$ level. This appears not to be the case for females; rather, being unmarried significantly reduces the probability of exiting to disability, and being a widow or divorced reduces the probability of exiting to unemployment.

Since husbands generally are older than their wives, there are more males (5-10\%, depending on states) than females (2-5\%) with dependent children (younger than 18 years) in our sample. Having dependent children tends to reduce the probability of early retirement for males, while the opposite is the case for females. As for the negative marginal effects for the males, this might have to do with the obligations following the role of being principal earner. There is, however, at least one other possible explanation. When having children to some degree prevent males from 
becoming disabled, it might be due to some selection mechanism where men with children have some unobserved attractive characteristic. Thus, in our reduced form model it is not possible to decide whether having children is a pure exogenous indicator, or, alternatively, if it is plagued by some endogeneity problems. So, based on our findings, we should not recommend men to have children just to increase their probability of staying employed and not becoming disabled.

Age has the expected effect that it increases the probability of early retirement. For both genders, the effect is strongest for the exit to disability and out of the labour force. The effects are marginally stronger for males compared to females.

We expect individuals with high human capital investment to be less inclined to early exit from the labour force. Our human capital variables, education and experience, both seem to represent insurance against disability and unemployment. The strongest effect is the females' (reduced) probability of exiting to disability.

Being a civil servant does not affect the probability of entering disability. It is, on the other hand, a remarkably good predictor for not becoming unemployed. This is probably due to few layoffs and the high degree of job protection for this occupational group. The variable in addition correlates positively with the probability of leaving the labour force for other reasons than disability and unemployment. The reason may be the higher use of AFP in the public sector than in the private sector.

The next section of Tables 3 and 4 presents the influence on early retirement from the income and wealth variables, which contain the main information on pecuniary relations of the individuals in our sample. Ideally, we need expected income streams in all the four states represented in our analysis. As explained earlier, this is modified by the fact that each individual can be observed in one state at the time only. By using previous earnings and labour market records, 
combined with the benefit and pension rules in force, we manage to construct income variables for the states work, disability and unemployment. We expect the own-effects to be positive (for example, high earnings reduce the probability of leaving a job), and the cross-effects to be negative (for example, high disability pension makes it less attractive to finance early retirement with unemployment benefits). As for earnings, our data clearly support our hypothesis. Increased earnings significantly reduce the probability of exit to any form of early retirement. ${ }^{18}$ Note that the response is approximately twice as strong for women compared to men. Furthermore, an increase in the unemployment benefits significantly reduces the males' probability of leaving to disability, and also has the expected positive own-effect on the females' probability of entering unemployment. For the remaining states there are no sizeable effects. Finally, increased disability pension significantly increases the probability of entering disability. But in addition, we estimate a counter-intuitive positive effect on both genders' propensity to exit to unemployment as well as out of the labour force.

The influence of (own) wealth on the retirement decision is not obvious, a priori. On the one hand, increased wealth will improve the possibility of early retirement through increased ability of self-support. There is a certain support for this effect in our data, in that the probability of exiting to out of the labour force increases, particularly for females. On the other hand, wealth may be a proxy for both ability and social status. In that case we would expect reduced probability of exit to early retirement to disability and unemployment. The negative reported marginal effect on males' propensity of exiting to disability is consistent with this view, but the positive effect on females' propensity of exiting to unemployment is not.

We also have data on several spouse characteristics, namely spouse age difference, spouse income and wealth, and a dummy for receiving pensions (old-age, disability or rehabilitation). 
Difference in age between the individuals and their spouses has no sizeable effect on the retirement behaviour. Two competing hypotheses are the added worker-effect versus assortative mating. If the added worker-effect dominates, we would expect compensating behaviour in the cases where the spouses have small resources. For example, if the spouse has low income and wealth, and/or is a pension receiver, this correlates with a low probability of early retirement, since it means that the other spouse must compensate by working extra hard and long. Our evidence is not clear-cut, but there seems to be rather weak support for the added worker-effect in our sample. High spouse income implies a significant reduction in the probability of early retirement for both males and females. ${ }^{19}$ Furthermore, having a spouse who is a pension receiver increases the probability of early retirement. Both findings clearly are consistent with the assortative mating hypothesis. As for spouse wealth, the picture is unclear, with insignificant coefficients in most of the cases.

In the estimations we control for employment in six different industries, with manufacturing as the base category. The most striking finding is that being employed in the manufacturing sector strongly increases the probability of unemployment retirement for males, and also has a significant effect on the probability of ending up as disabled. The number of females employed in this sector is relatively low, which probably explains the lack of such a finding for this group. Furthermore, working in the education and health sectors represents strong protection against unemployment, the explanation probably being the same as for civil servants.

The year dummies $(1989=0)$ are meant to take care of the timing and magnitude of business cycles, as well as structural changes in the form of modifications and adjustments of the rules in force. For men there are mostly positive and significant effects on the transitions to disability and unemployment, and negative effects on the probability of staying in work, especially for the years 1992, 1993 and 1994. The pattern is the opposite for women, with negative effects for disability, 
unemployment, and out of work, and positive effects for work. This lack of gender coincidence is somewhat puzzling. The institutional changes relevant for early retirement (changes in eligibility criteria, introduction AFP, etc.) are in general gender neutral. Similarly, both genders are faced with the same business cycles. The explanation is probably the fact that males and females work in different sectors. Institutional changes and the business cycles hit the sectors differently, more so than we are able to pick up with the rather crude sector dummies previously referred to.

Finally, we control for some local municipality characteristics. With the two first variables we test whether the behaviour differs systematically in urban compared to rural areas. Our data hardly support this hypothesis. Most of the marginal effects are insignificant, and in the cases where we report sizeable effects (out of labour force for males, disability for females), the variables point in opposite directions. As for the local unemployment rate, this turns out to be an important predictor for the probability of early retirement in the form of unemployment. ${ }^{20}$ Interestingly, local unemployment rate also correlates positively with the state of disability. This is, in itself, a support to the argument that unemployment and disability are substitutable pathways to early retirement, and that there is an over-utilisation going on in the form of unemployed individuals ending up in disability retirement without being truly disabled. ${ }^{21}$

To visualise our findings, we present some simulations where we predict the probability of exiting to disability and unemployment as we change the values of certain variables, while all other variables are kept fixed at their (sample) mean values. Among the continuous and categorical variables (for obvious reasons the dichotomous variables are not usable for this purpose), we have chosen two variables with relevance for policy purposes. These variables are education and earnings. Following the order of presentation from Tables 3 and 4, we start with the education variable. 
(Figure 3 about here)

The zero point on the horizontal axis represents the mean education for the two genders. Since the simulations are performed with all the other covariates kept fixed at their mean level, this point corresponds to the yearly mean exit probability. The marginal effects on disability as well as unemployment are strongest for females (-. 004 and -. 002, vs. -. 002 and -. 0003 for males, respectively), which explains the steeper curves for women. According to our figures a three year increase, say, in the average level of education will reduce the probability of early retirement in the form of disability by more than one percentage point for the females (from 4.8 to 3.6 ), while the corresponding reduction for males is only 0.8 percentage point. While there is practically no effect of increased education on the hazard to unemployment for males, the unemployment rate for females falls from 2.3 to 1.7 for the example in question.

(Figure 4 about here)

Also the effects of earnings on disability and unemployment exits are much higher for females compared to males (-. 008 and -. 003 vs. -. 004 and -. 001, respectively). In Figure 4 we illustrate the effects of equal increases in amounts for each gender. Hence, since average yearly earnings for males are about NOK 221,000 and about 131,000 for females, each step represents a relatively larger increase for the latter. In this respect Figure 4 illustrates the effect of a policy where the relative gender gap in earnings is reduced successively. Based on the estimated marginal effects an increase of NOK 10,000 will bring the females' probability of exiting to disability down to the 
males' level. Another increase of the same amount will lead to a stipulated reduction in disability probability of 0.65 percentage points, while the corresponding effect for males is 0.4 percentage points only. The figure reflects the same pattern for the probability of exiting to unemployment, albeit with a smaller effect for both genders.

As will always be the case in regression analysis, the reported gender differences in the predicted exit probabilities are a mix of differences in the values of the explanatory variables and in the values of the estimated parameters, respectively. One way of disentangling the two sources, is to calculate the females' (counterfactual) probabilities of ending in the various states using the female sample-characteristics together with the estimated coefficients-vector from the multinomial logit model estimation for males. The same procedure is performed on males, and both experiments are reported in Table 5.

(Table 5 about here)

The new probabilities for females are $82.0 \%, 11.0 \%, 4.9 \%$, and $2.1 \%$ (work, disability, unemployment, and out of work, respectively). Note that the probabilities of ending in the states disability and unemployment are more than doubled if the females (with their given characteristics) respond similarly to males. Interestingly, there seems to be no parallel effect when we substitute the females' coefficients with the male characteristics (right half of Table 5).

\section{Discussion}


The labour attachment for males and females may, at first glance, seem to be growing more and more equal in Norway. The participation rates for females are increasing, particularly for the youngest. The participation rates for older males are, on the other hand, falling. Therefore, it is important that we ask whether younger women will adopt men's retirement pattern, as they grow older. Our micro evidence suggests that there may be several reasons why this will not be the case.

The family structure is changing in the Western countries. A dramatic increase in the dissolution of marriages and cohabitation steadily increases the number of single-person households. While being single appears to increase the probability of early exit for males, there is some evidence that the opposite seems to be the case for females. Secondly, a relatively safe prediction is that females will acquire relatively more education in the years to come. ${ }^{22}$ Increased human capital in the form of education will probably reduce the earnings gender gap (at least this appears to be the case in Norway). Our findings indicate that females are responding more strongly to changes in education as well as earnings. The higher (expected) levels and the higher (estimated) responses both point in the direction of reduced probability of early retirement. Thirdly, while males tend to work in sectors with relatively high exit rates to disability and unemployment, notably manufacturing and construction, females far more often work in sectors with a relatively low occurrence of disability and unemployment, such as health and education. Moreover, these are sectors that are expected to have a growing employment in the coming decades. All these findings indicate that the propensity to retire early will be lower for females than for males for the cohorts to come.

Some reservations have to be made, however. Our results are based on a sample of people that have selected themselves; first, into employment, and thereafter into the different states we evaluate. There are, of course, lots of unobservable phenomena involved in the individual choices. A particularly relevant example is the selection of women in our sample. When we propose that future 
female cohorts will have lower propensity of early retirement, it builds on the assumption that they will behave and respond equivalently to the women we include in our analysis, namely the 19291934 cohorts. We do not know that the younger female cohorts in today's work force respond equally strongly to increased earnings, education, experience, etc. On the contrary, even if Norway has a relatively high participation rate for older female cohorts, it is reasonable to assume that they are a selection with stronger abilities and/or motivation for participation in the work force than the ones that comprise the younger female labour force. The selection problem will be at the core of our future research.

\section{References}

Altonji, J. G. and Blank, R. M. (1999) Race and gender in the labor market. In: Ashenfelter, O. and Card, D. (eds.) Handbook of Labor Economics Volume 3C (pp. 3143-3259). Amsterdam, North Holland, Elsevier Science.

Berkovec, J. and Stern, S. (1991) Job exit behavior of older men. Econometrica, 59, 189-210.

Blau, D. M. (1994) Labour force dynamics of older men. Econometrica, 62, 117-156.

Blöndal, S. and Scarpetta, S. (1998) The Retirement Decision in OECD Countries. Working Paper AWP 1.4. OECD, Paris.

Boskin, M. J. and Hurd, M. D. (1978) The effect of social security on early retirement. Journal of Public Economics, 10, 361-377.

Bratberg, E., Holmås, T. H. and Thøgersen, Ø. (2000) Assessing the effects of early retirement programs. Mimeo. Department of Economics, University of Bergen.

Bratberg, E. (1996) Short run exits from long term sickness. In: Bratberg, E.: Incentives in Social Insurance. Dissertations in Economics, No. 11. Department of Economics, University of Bergen.

Dahl, S. Å., Nilsen, Ø. A. and Vaage, K. (2000) Work or retirement? Exit routes for Norwegian elderly. Applied Economics, 32, 1865-1876.

Even, W. E. and Macpherson, D. A. (1990) The gender-gap in pensions and wages. Review of Economics and Statistic, 72, 259-265. 
Even, W. E. and Macpherson, D. A. (1994) Gender differences in pensions. Journal of Human Resources, 29, 555-587.

Farkas, J. I. and O'Rand, A. M. (1998) The pension mix for women in middle and late life: The changing employment relationship. Social Forces, 76, 1007-1032.

Feuerbach, E. J. and Erwins, C. J. (1994) Women's retirement: The influence of work history. Journal of Women \& Aging, 6, 69-85.

Fox, J. (1977) Effects of retirement and former work life on women's adaptation in old age. Journal of Gerontology, 32, 232-240.

Gruber, J. and Wise, D. (1998) Social security and retirement: An international comparison. American Economic Review, 88 (Papers and Proceedings), 158-163.

Hatch, L. R. and Thompson, A. (1992) Family responsibilities and women's retirement. In: Szinovacz, M., Ekerdt, D. and Vinick, B. (eds.) Families and Retirement (pp. 81-98). Sage Publications, Newbury Park, CA.

Haveman, R., Wolfe, B., and Warlick, J. (1988) Labor market behavior of older men. Estimates from a trichotomous choice model. Journal of Public Economics, 36, 153-175.

Hayward, M. D., Hardy, M. A., and Grady, W. R. (1989) Labor force withdrawal patterns among older men in the United States. Social Science Quarterly, 70, 425-448.

Henkens, K., Kraaykamp, G. and Siegers, J. (1993) Married couples and their labour market status. European Sociological Review, 9, 67-79.

Henretta, J. C., O'Rand, A. M. and Chan, C. G. (1993) Joint role investments and synchronization of retirement: A sequential approach to couples' retirement timing. Social Forces, 71, 9811000 .

Hernæs, E., Sollie, M. and Strøm, S. (2000) Early retirement and economic incentives. Scandinavian Journal of Economics, 102, 481-502.

Kohli, M. and Rein, M. (1991) The changing balance of work and retirement. In: Kohli, M., Rein, M., Guillemard, A.M. and van Gunstern, H. (eds.) (pp. 1-35) Time for Retirement. Comparative Studies of Early Exit from the Labour Force. Cambridge, Camridge University Press.

Lilja, R. (1996) Microeconomic analysis of early retirement in Finland. In: Wadensjö, E. (ed.) Leaving the Labour Market Early in the Welfare State (pp. 157-173). Amsterdam, Elsevier Science Publishers.

Matthews, S. and Brown, D. (1987) Retirement as a crucial life event: The differential experiences of women and men. Research on Aging, 9, 548-551. 
Meghir, C. and Whitehouse, E. (1997) Labour market transitions and retirement of men in the UK. Journal of Econometrics, 79, 327-354.

O'Rand, A., Henretta, J. and Krecker, M (1992) Family pathways to retirement. In: Szinovacz, M., Ekerdt, D. and Vinick, B. (eds.) Families and Retirement (pp. 81-98). Sage Publications, Newbury Park, CA.

Pedersen, P. J. and Smith, N. (1996) A duration analysis of the decision to retire early. In: Wadensjö, E. (ed.) Leaving the Labour Market Early in the Welfare State (pp. 131-155). Amsterdam, Elsevier Science Publishers.

Peracchi, F. and Welch, F. (1994) Trends in labour force transitions of older men and women. Journal of Labour Economics, 12, 210-242.

Quinn, J. F. and Kozy, M. (1996) The role of bridge jobs in the retirement transition: Gender, race, and ethnicity. The Gerontologist, 3, 363-372.

Reitzes, D. C., Mutran, E. J. and Fernandes, M. E. (1998) The decision to retire: A career perspective. Social Science Quarterly, 79, 607-619.

Richardson, V.E. (1993) Retirement Counceling. New York, Springer Publishing Company.

Riphahn, R. T. (1997) Disability retirement and unemployment - substitute pathways for labour force exit? An empirical test for the case of Germany. Applied Economics, 29, 551-561.

Ruhm, C. J. (1990) Brigde jobs and partial retirement. Journal of Labour Economics, 8, 482501.

Ruhm, C. J. (1996) Gender differences in employment behaviour during late middle age. Journal of Gerontology, 51B, S11-S17.

Spilerman, S. and Petersen, T. (1999) Organizational structure, determinants of promotion, and gender differences in attainment. Social Science Research, 28, 203-227.

Szinovacz, M. and Ekerdt, D. (1995) Families and retirement. In: Blieszner, R. and Hilkevitch Bedford, V. (eds.) Handbook of aging and the family (pp. 376-400). Greenwood Press, Westport, Connecticut.

Talaga, J. A. and Behr, T. A. (1995) Are there gender differences in predicting retirement decisions? Journal of Applied Psychology, 80, 16-28.

The Economist (1999) A full life. September $4^{\text {th }}, 352,75-77$.

Ultee, W., Dessens, J. and Jansen, W. (1988) Why does unmployment come in couples? European Sociological Review, 4, 111-112. 
Villani, P. J. and Roberto, K. A. (1997) Retirement decision-making: Gender issues and policy implications. Journal of Women \& Aging, 9, 151-163.

Vistnes, J. P. (1994) An empirical analysis of married women's retirement decisions. National Tax Journal, 47, 135-164.

Wadensjö, E. (1996) The Nordic Labour Markets in the 1990s. Amsterdam, Elsevier Science Publications.

Yabiku, S. T. (2000) Family history and pensions: The relationships between marriage, divorce, children, and private pension coverage. Journal of Aging Studies, 14, 293-312. 


\section{Notes}

${ }^{1}$ The "added worker" effect describes behaviour where the labour supply increases when the spouse's income is reduced or disappears. The "assortative mating" effect describes behaviour where the partners have the same preferences, i.e. the labour supply of the two spouses are positively correlated.

${ }^{2}$ There are several reasons for this, among these are data limitations, but it has also been argued that a prominent reason is that the work role for women has been viewed as a secondary role (Fox, 1977; Villani and Roberto, 1997). There are notable exceptions, however, and some studies focus only on females (e.g. Farkas and O'Rand, 1998; Feuerbach and Erdwins, 1994; Vistnes, 1994).

${ }^{3}$ This finding is supported by other studies, which also show that the probability of taking early retirement is higher if the spouse has already retired (and if friends have already retired) (e.g. Reitzes, Mutran, and Fernandez; Henkens and Tazelaar, 1994; Henretta and O'Rand, 1983).

${ }^{4}$ A positive relationship between the labour market status of partners is also found for married couples receiving disability benefits (Henkens, Kraaykamp, and Siegers, 1993) and unemployment insurance (Ultee, Dessens, and Jansen, 1988).

${ }^{5}$ See Dahl, Nilsen and Vaage (2000) for a more thorough discussion of the occupation specific arrangements.

${ }^{6}$ AFP covers employees organised in labour unions in firms that are organised in the Norwegian Employers' Federation (NHO) and public employees.

${ }^{7}$ The replacement rate is commonly defined as the benefits-to-income ratio $(B / W)$, i.e. the fraction of the previous earnings which the benefits replace. The replacement rate we use here is the before-tax (gross) replacement rate. The after-tax replacement rate (net) is higher, especially for disability pension, because of the tax laws.

${ }^{8}$ KIRUT is a Norwegian acronym that roughly translates to "Clients into and through the Social Insurance System".

${ }^{9}$ We have chosen the oldest cohort to be the 1929 cohort. These individuals will be between 65 and 66 years old in our last sample year; they are thus not entitled to an old-age pension.

${ }^{10}$ If the individuals have a temporary spell with either sickness absence or rehabilitation, we consider them to still be working.

${ }^{11}$ This ranking was chosen since we consider the quality of the disability data to be more reliable than that of the unemployment data.

${ }^{12}$ Ideally, private early retirement schemes and AFP, would be included as additional pathways in our study. However, data on private schemes are not available. The National Insurance Administration has some data on AFP retirees, but mainly from 1995 and onward. During most of the period we are studying, disability pension and unemployment insurance were the most important early retirement schemes. In 1995 there were 134.000 disability pensioners between 55 and 67 years, 7,000 received unemployment insurance while 9,000 received an AFP-pension (increased from 2,500 in 1990).

${ }^{13} \mathrm{G}$ is the basic unit used in the pension system, NOK 32,275 in $1989(€ 4,000)$.

${ }^{14}$ The function for calculating income as disabled includes an individual's age, aggregate pension points, marital status and whether one's spouse is benefit receiver or not as arguments. See Bratberg (1996) for details.

${ }^{15}$ NOK $8 \approx € 1$.

${ }^{16}$ There have also been changes in the AFP retirement in the years after the end of the sample period (see section 3).

${ }^{17}$ On the other hand, long working experience also implies a high degree of pension rights, which, ceteris paribus, makes a person more inclined to early retirement.

${ }_{18}$ The only exception is the males' probability of exiting to "out of labour force", which is reduced, but not significantly.

${ }^{19}$ There are examples of positive effects, but they are never statistically significant.

${ }^{20}$ There is a potential simultaneity problem here if, for a given municipality, the number of unemployed in our sample is large enough to contribute significantly to our measure of local unemployment rate. Since our sample only consists of 7 cohorts, and - not least-since we only register long-term unemployment, we believe this to be a minor problem.

${ }^{21}$ Note, however, that the question of unemployment and disability being exchangeable pathways to early retirement is a more complex one than what can be seen from from the marginal effects of the local unemployment ratio. Based on a battery of Wald tests Dahl, Nilsen and Vaage (2000) reject the substitutability hypothesis, as does Riphahn (1997) on German data. 
${ }^{22}$ For younger Norwegian cohorts women have already passed men when it comes to length of education. 


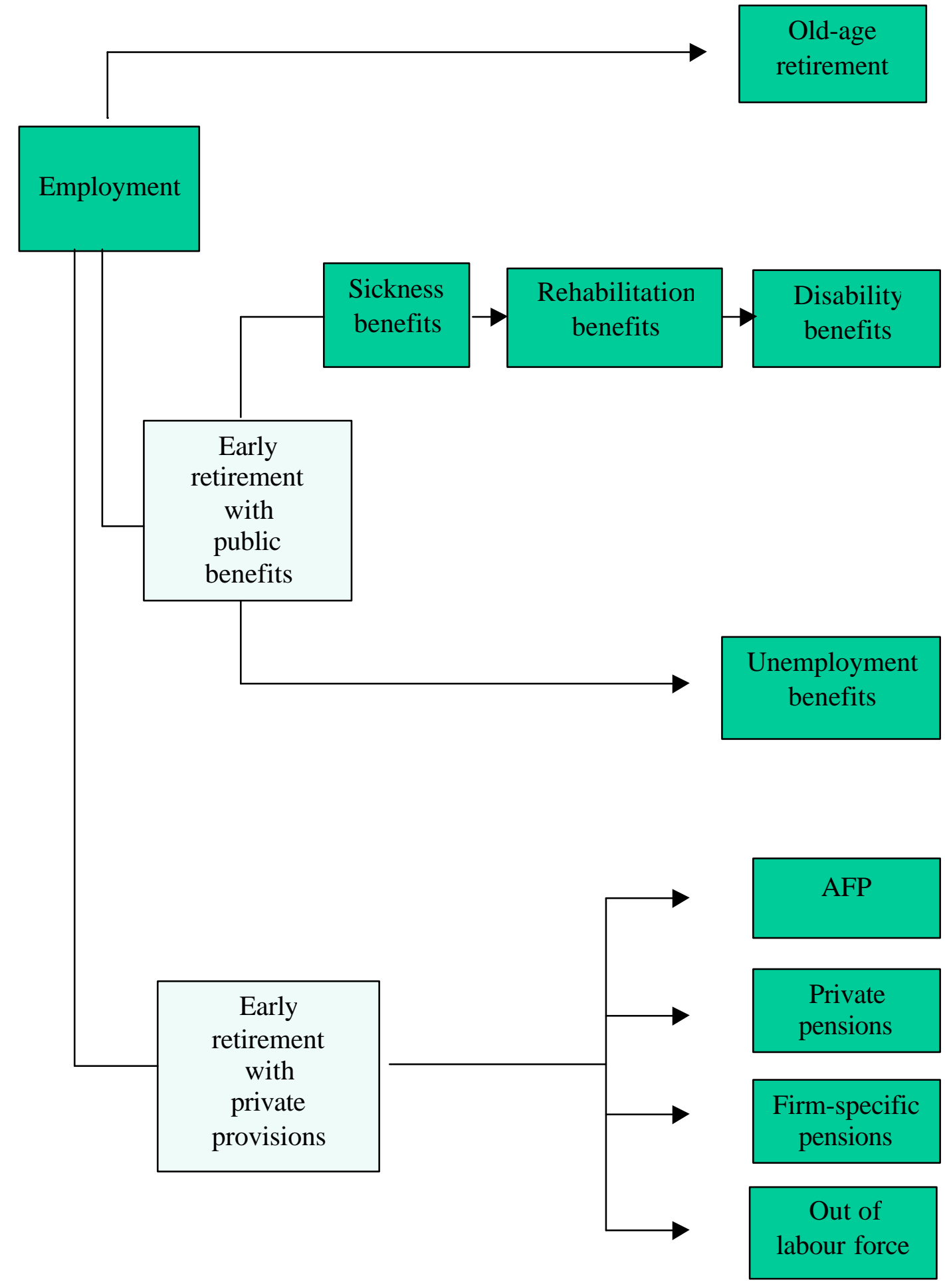

\section{Figure 1. Exit routes in Norway}




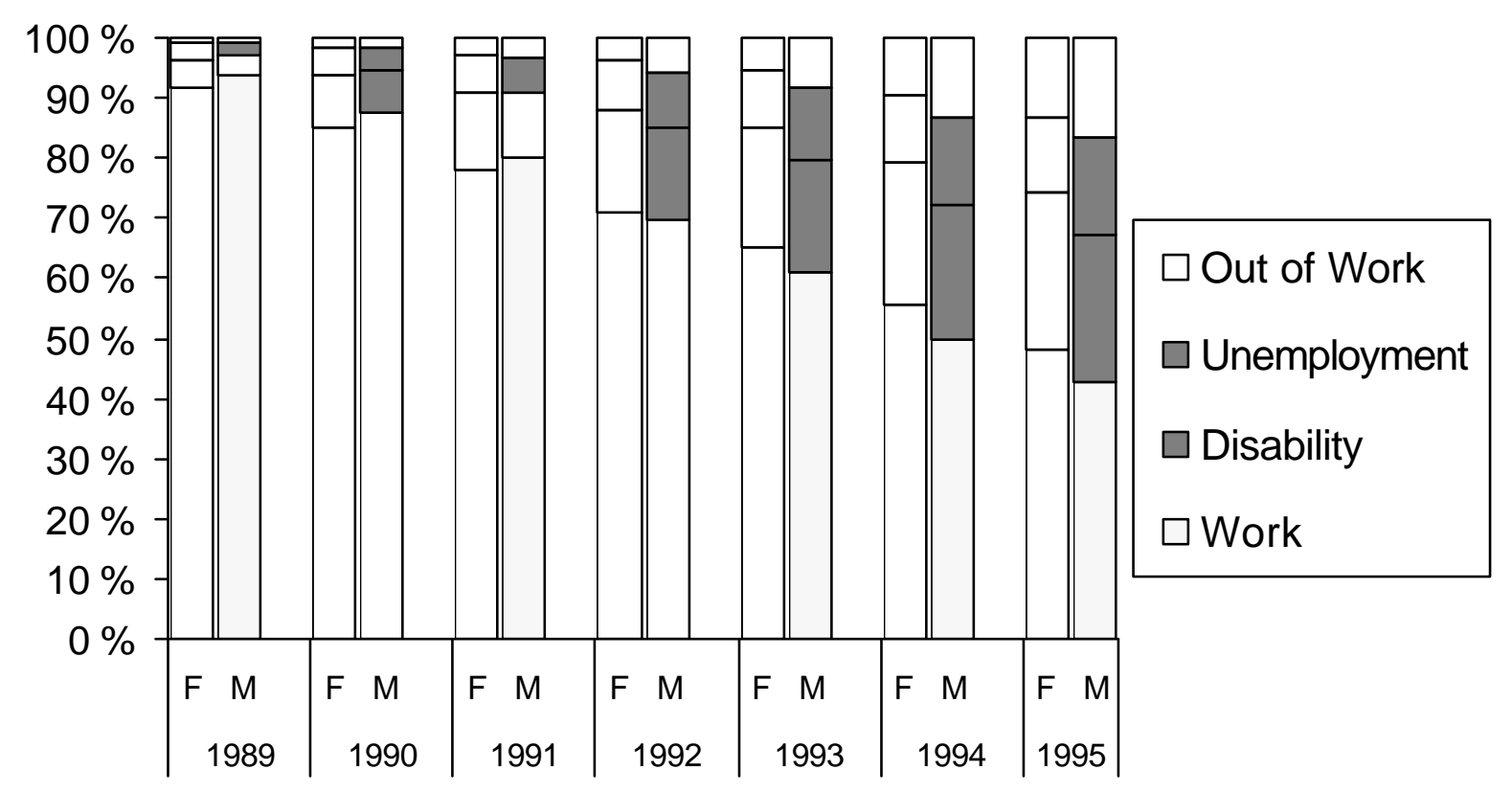

Figure 2. Individuals in various end states, accumulated, by gender 


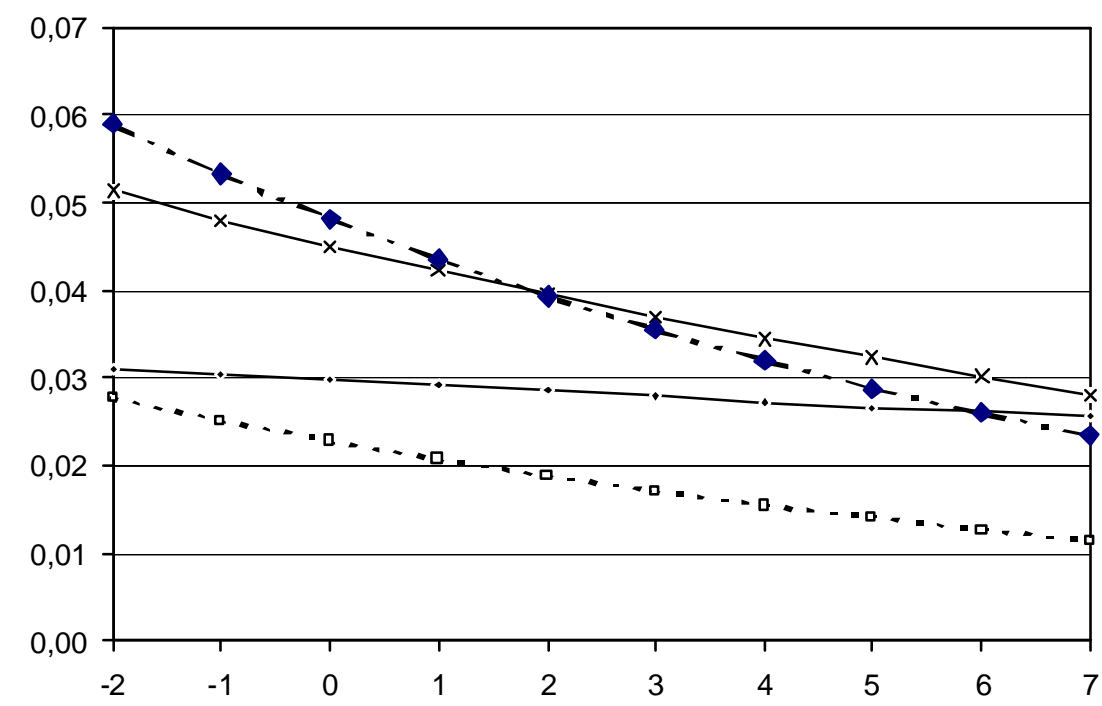

$\longrightarrow \times$-Disability, $M$

-_-Unemployment, M

$\longrightarrow$ - Disability, F

- - - - Unemployment, F

Figure 3. Education, males and females

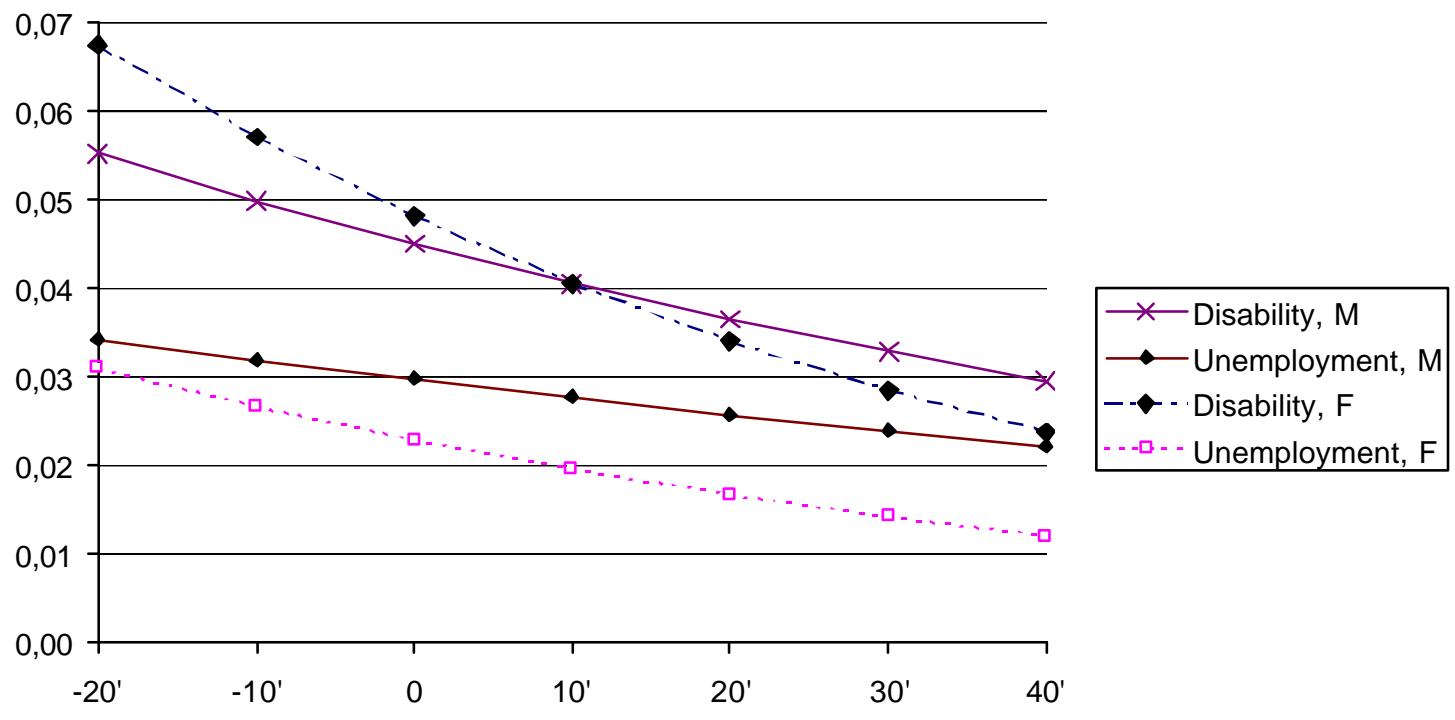

Figure 4. Earnings, males and females 
Table 1. Exit probabilities (percentage)

Females

$\begin{array}{rrrrrr}\text { Year } & \text { Disability } & \text { Unemploy. } & \text { Out of work } & \text { Work } & \text { Total } \\ 1989 & 4.4 & 3.0 & 0.9 & 91.7 & 4932 \\ 1990 & 4.8 & 1.7 & 1.0 & 92.6 & 4523 \\ 1991 & 4.9 & 2.0 & 1.3 & 91.7 & 4188 \\ 1992 & 5.1 & 2.5 & 1.1 & 91.3 & 3842 \\ 1993 & 4.2 & 2.1 & 2.2 & 91.5 & 3506 \\ 1994 & 5.5 & 2.4 & 6.4 & 85.6 & 3208 \\ 1995 & 5.1 & 2.3 & 6.4 & 86.2 & 2747 \\ \text { Weighted prob. } & 4.8 & 2.3 & & & 90.5 \\ \end{array}$

Males

\begin{tabular}{|c|c|c|c|c|}
\hline Year & Disability & Unemploy. & Out of work & Work \\
\hline 1989 & 3.3 & 2.1 & 0.8 & 93.7 \\
\hline 1990 & 4.1 & 1.5 & 1.1 & 93.3 \\
\hline 1991 & 4.3 & 2.5 & 1.7 & 91.4 \\
\hline 1992 & 5.7 & 4.1 & 2.9 & 87.3 \\
\hline 1993 & 4.5 & 4.6 & 3.7 & 87.2 \\
\hline 1994 & 6.0 & 3.8 & 8.0 & 82.1 \\
\hline 1995 & 4.2 & 3.1 & 7.1 & 85.6 \\
\hline prob. & 4.5 & 3.0 & 3.1 & 89.4 \\
\hline
\end{tabular}

Common All the probabilities are calculated conditional on the number of individuals notes: $\quad$ working at the beginning of each year. 


\begin{tabular}{|c|c|c|c|c|c|c|c|c|}
\hline & \multicolumn{4}{|c|}{ Females } & \multicolumn{4}{|c|}{ Males } \\
\hline & $\begin{array}{r}\text { Dis- } \\
\text { ability }\end{array}$ & $\begin{array}{l}\text { Un- } \\
\text { ploy. }\end{array}$ & $\begin{array}{c}\text { Out of } \\
\text { work }\end{array}$ & Work & $\begin{array}{r}\text { Dis- } \\
\text { ability }\end{array}$ & $\begin{array}{l}\text { Un- } \\
\text { ploy. }\end{array}$ & $\begin{array}{r}\text { Out of } \\
\text { work }\end{array}$ & Work \\
\hline \multicolumn{9}{|l|}{ Personal characteristics } \\
\hline Married & 0.71 & 0.78 & 0.73 & 0.73 & 0.79 & 0.79 & 0.81 & 0.85 \\
\hline Unmarried & 0.04 & 0.05 & 0.07 & 0.06 & 0.07 & 0.08 & 0.05 & 0.05 \\
\hline Widow/widower & 0.14 & 0.12 & 0.15 & 0.13 & 0.04 & 0.04 & 0.05 & 0.03 \\
\hline Divorced & 0.10 & 0.06 & 0.05 & 0.09 & 0.10 & 0.10 & 0.09 & 0.08 \\
\hline Children (1=yes) & 0.03 & 0.05 & 0.02 & 0.03 & 0.06 & 0.08 & 0.04 & 0.09 \\
\hline Age & 59.4 & 59.0 & 61.5 & 58.9 & 59.5 & 59.6 & 61.1 & 58.8 \\
\hline Education & 9.1 & 8.8 & 9.9 & 9.9 & 9.5 & 9.7 & 10.8 & 10.8 \\
\hline Experience & 18.6 & 17.2 & 20.9 & 18.6 & 24.6 & 24.8 & 25.9 & 24.3 \\
\hline Civil servant (1=yes) & 0.1 & 0.0 & 0.3 & 0.2 & 0.1 & 0.0 & 0.4 & 0.2 \\
\hline \multicolumn{9}{|l|}{ Income (as) and wealth } \\
\hline Employed (10,000 NOK) & 11.9 & 11.2 & 12.5 & 13.1 & 18.5 & 19.6 & 22.3 & 22.1 \\
\hline Unemploy. (10,000 NOK) & 7.6 & 7.2 & 7.9 & 8.1 & 11.6 & 11.7 & 12.3 & 12.1 \\
\hline Disabled (10,000 NOK) & 6.3 & 6.0 & 6.5 & 6.7 & 9.6 & 9.9 & 10.5 & 10.5 \\
\hline Wealth $(10,000$ NOK $)$ & 12.0 & 14.4 & 20.5 & 13.9 & 22.6 & 29.1 & 66.7 & 29.6 \\
\hline \multicolumn{9}{|l|}{ Spouse characteristics } \\
\hline Spouse age difference $\left.{ }^{\star}\right)$ & -3.3 & -3.5 & -3.0 & -3.5 & 3.3 & 3.2 & 3.5 & 3.2 \\
\hline Income $(10,000 \mathrm{NOK})^{\star)}$ & 14.4 & 11.1 & 14.1 & 10.5 & 8.8 & 6.9 & 8.0 & 7.8 \\
\hline Wealth $\left.(10,000 \text { NOK })^{\star}\right)$ & 31.9 & 26.3 & 26.3 & 39.7 & 7.3 & 6.1 & 7.0 & 24.3 \\
\hline Benefit receiver $\left.(1=\text { yes })^{*}\right)$ & 0.3 & 0.4 & 0.3 & 0.5 & 0.1 & 0.2 & 0.2 & 0.2 \\
\hline \multicolumn{9}{|l|}{ Industries } \\
\hline Agricult.+ Fisheries & 0.01 & 0.01 & 0.01 & 0.01 & 0.01 & 0.01 & 0.01 & 0.01 \\
\hline Manufac. + Construction & 0.24 & 0.34 & 0.19 & 0.20 & 0.57 & 0.69 & 0.32 & 0.43 \\
\hline Private services & 0.21 & 0.33 & 0.16 & 0.18 & 0.11 & 0.13 & 0.07 & 0.12 \\
\hline Transport and commu. & 0.03 & 0.03 & 0.08 & 0.05 & 0.08 & 0.04 & 0.22 & 0.11 \\
\hline Real estate + Finance & 0.04 & 0.06 & 0.07 & 0.06 & 0.05 & 0.05 & 0.06 & 0.07 \\
\hline Education + Health & 0.46 & 0.24 & 0.49 & 0.50 & 0.18 & 0.09 & 0.32 & 0.27 \\
\hline \multicolumn{9}{|l|}{ Local municipality } \\
\hline Residence density & 6.9 & 6.6 & 7.2 & 7.0 & 6.9 & 6.9 & 7.1 & 7.2 \\
\hline Distance to center & 5.4 & 5.3 & 5.8 & 5.7 & 5.4 & 5.4 & 5.7 & 5.6 \\
\hline Unemployment rate & 0.06 & 0.06 & 0.06 & 0.06 & 0.06 & 0.06 & 0.06 & 0.06 \\
\hline \multirow{2}{*}{$\begin{array}{l}\text { Number of observations } \\
\text { Number of individuals at } \\
\text { the end of } 1995\end{array}$} & 1300 & 617 & 648 & 24381 & 1314 & 869 & 897 & 26082 \\
\hline & 1300 & 617 & 648 & 2367 & 1314 & 869 & 897 & 2303 \\
\hline
\end{tabular}

*) Means calculated conditional on being married 
Table 3. Marginal effects. Multinomial logit model, females

\begin{tabular}{|c|c|c|c|c|c|c|c|c|}
\hline \multirow{2}{*}{ Personal characteristics } & \multicolumn{2}{|c|}{ Disability } & \multicolumn{2}{|c|}{ iemploy. } & \multirow{2}{*}{\multicolumn{2}{|c|}{ Out of work }} & \multicolumn{2}{|c|}{ Work } \\
\hline & & & & & & & & \\
\hline Unmarried & -0.0191 & -2.766 & -0.0036 & -1.034 & 0.0011 & 0.432 & 0.0217 & 2.684 \\
\hline Widow/widower & -0.0071 & -1.397 & -0.0066 & -2.573 & -0.0007 & -0.333 & 0.0143 & 2.401 \\
\hline Divorced & 0.0066 & 1.216 & -0.0055 & -1.705 & -0.0041 & -1.504 & 0.0030 & 0.438 \\
\hline Children (1=yes) & 0.0036 & 0.518 & 0.0061 & 2.018 & 0.0008 & 0.200 & -0.0105 & -1.236 \\
\hline Age & 0.0039 & 5.399 & 0.0009 & 2.175 & 0.0052 & 14.577 & -0.0100 & -11.160 \\
\hline Education & -0.0045 & -7.403 & -0.0015 & -4.451 & 0.0001 & 0.573 & 0.0059 & 8.054 \\
\hline Experience & -0.0010 & -3.025 & -0.0006 & -3.570 & 0.0003 & 1.836 & 0.0014 & 3.326 \\
\hline Civil servant ( $1=y e s)$ & -0.0036 & -0.925 & -0.0198 & -6.079 & 0.0072 & 5.135 & 0.0162 & 3.124 \\
\hline \multicolumn{9}{|l|}{ Income (as) and wealth } \\
\hline Employed (10,000 NOK) & -0.0077 & -9.320 & -0.0025 & -5.775 & -0.0011 & -3.134 & 0.0113 & 11.005 \\
\hline Unemploy. (10,000 NOK) & 0.0007 & 0.693 & 0.0026 & 4.754 & -0.0006 & -1.422 & -0.0027 & -2.155 \\
\hline Disabled (10,000 NOK) & 0.0189 & 8.383 & 0.0027 & 2.148 & 0.0021 & 2.014 & -0.0236 & -8.474 \\
\hline Wealth (10 000 NOK) & -0.0001 & -1.248 & 0.0001 & 2.777 & 0.0000 & 2.614 & 0.0000 & -0.136 \\
\hline \multicolumn{9}{|l|}{ Spouse characteristics } \\
\hline Spouse age difference & 0.0004 & 1.033 & 0.0002 & 0.784 & -0.0002 & -0.909 & -0.0004 & -0.876 \\
\hline Income $(10,000$ NOK $)$ & -0.0005 & -2.956 & 0.0001 & 1.249 & -0.0001 & -0.932 & 0.0005 & 2.447 \\
\hline Wealth $(10,000$ NOK $)$ & -0.0001 & -1.505 & -0.0001 & -2.520 & 0.0000 & 1.231 & 0.0001 & 2.229 \\
\hline Benefit receiver (1=yes) & 0.0236 & 5.180 & 0.0017 & 0.706 & 0.0031 & 1.588 & -0.0283 & -5.196 \\
\hline \multicolumn{9}{|l|}{ Industries } \\
\hline Agricult.+ Fisheries & 0.0034 & 0.270 & -0.0012 & -0.200 & 0.0038 & 0.628 & -0.0060 & -0.391 \\
\hline Private services & -0.0023 & -0.624 & 0.0012 & 0.726 & -0.0014 & -0.802 & 0.0025 & 0.584 \\
\hline Transport and commu. & -0.0281 & -3.675 & -0.0048 & -1.175 & 0.0049 & 2.078 & 0.0280 & 3.164 \\
\hline Real estate + Finance & -0.0152 & -2.418 & -0.0053 & -1.822 & 0.0051 & 2.211 & 0.0154 & 2.123 \\
\hline Education + Health & -0.0040 & -1.311 & -0.0154 & -9.111 & -0.0013 & -0.930 & 0.0208 & 5.524 \\
\hline \multicolumn{9}{|l|}{ lummies } \\
\hline 1990 & -0.0008 & -0.201 & -0.0100 & -4.491 & -0.0042 & -1.528 & 0.0151 & 2.805 \\
\hline 1991 & -0.0015 & -0.337 & -0.0074 & -3.254 & -0.0053 & -1.943 & 0.0142 & 2.533 \\
\hline 1992 & -0.0015 & -0.303 & -0.0040 & -1.656 & -0.0123 & -4.071 & 0.0178 & 2.875 \\
\hline 1993 & -0.0124 & -2.220 & -0.0069 & -2.480 & -0.0090 & -3.077 & 0.0283 & 4.152 \\
\hline 1994 & -0.0020 & -0.351 & -0.0030 & -1.020 & 0.0001 & 0.043 & 0.0049 & 0.700 \\
\hline 1995 & -0.0093 & -1.456 & -0.0038 & -1.164 & -0.0049 & -1.648 & 0.0180 & 2.340 \\
\hline \multicolumn{9}{|l|}{ Local municipality } \\
\hline Residence density & 0.0011 & 1.825 & -0.0001 & -0.414 & 0.0003 & 1.207 & -0.0012 & -1.801 \\
\hline Distance to center & -0.0016 & -2.415 & -0.0003 & -0.862 & 0.0003 & 0.980 & 0.0016 & 1.974 \\
\hline Unemployment rate & 0.1563 & 2.169 & 0.1461 & 4.074 & -0.0080 & -0.241 & -0.2944 & -3.388 \\
\hline Constant & -0.3160 & -7.395 & -0.0769 & -3.325 & -0.3581 & -16.498 & 0.7510 & 14.280 \\
\hline Nbr. of observations & 1300 & & 617 & & 648 & & 24381 & \\
\hline Pseudo I & & & & & & & & \\
\hline Log Likelihood & 28 & & & & & & & \\
\hline
\end{tabular}


Table 4. Marginal effects. Multinomial logit model, males

\begin{tabular}{|c|c|c|c|c|c|c|c|c|}
\hline \multirow{2}{*}{ Personal characteristics } & \multicolumn{2}{|c|}{ Disability } & \multicolumn{2}{|c|}{ Unemploy. } & \multicolumn{2}{|c|}{ Out of work } & \multicolumn{2}{|c|}{ Work } \\
\hline & & & & & & & & \\
\hline Unmarried & -0.0038 & -0.862 & 0.0037 & 1.721 & 0.0042 & 1.459 & -0.0041 & -0.714 \\
\hline Widow/widower & -0.0041 & -0.769 & 0.0002 & 0.064 & 0.0001 & 0.029 & 0.0038 & 0.566 \\
\hline Divorced & 0.0028 & 0.746 & 0.0043 & 2.283 & 0.0021 & 0.875 & -0.0092 & -1.900 \\
\hline Children(1=yes) & -0.0092 & -2.206 & 0.0015 & 0.814 & -0.0049 & -1.680 & 0.0126 & 2.355 \\
\hline Age & 0.0045 & 7.724 & 0.0012 & 4.003 & 0.0059 & 15.229 & -0.0116 & -15.254 \\
\hline Education & -0.0024 & -5.757 & -0.0003 & -1.631 & -0.0013 & -5.604 & 0.0041 & 7.773 \\
\hline Experience & -0.0027 & -2.797 & -0.0014 & -2.978 & 0.0001 & 0.070 & 0.0040 & 2.583 \\
\hline Civil servant (1=yes) & -0.0015 & -0.502 & -0.0411 & -14.913 & 0.0139 & 9.025 & 0.0288 & 6.680 \\
\hline \multicolumn{9}{|l|}{ Income (as) and wealth } \\
\hline Employed (10,000 NOK) & -0.0038 & -9.442 & -0.0011 & -5.499 & -0.0002 & -1.081 & 0.0051 & 10.698 \\
\hline Unemploy. (10,000 NOK) & -0.0036 & -3.392 & -0.0007 & -1.360 & 0.0011 & 1.320 & 0.0033 & 2.232 \\
\hline Disabled $(10,000$ NOK $)$ & 0.0081 & 5.065 & 0.0031 & 3.900 & 0.0020 & 2.281 & -0.0132 & -6.670 \\
\hline Wealth $(10,000$ NOK $)$ & -0.0001 & -2.541 & 0.0000 & 1.261 & 0.0000 & 1.290 & 0.0001 & 2.463 \\
\hline \multicolumn{9}{|l|}{ Spouse characteristics } \\
\hline Spouse age difference & 0.0000 & -0.039 & 0.0000 & 0.185 & -0.0002 & -0.972 & 0.0001 & 0.440 \\
\hline Income $(10,000 \mathrm{NOK})$ & -0.0007 & -3.860 & 0.0001 & 0.687 & -0.0003 & -2.862 & 0.0010 & 4.151 \\
\hline Wealth $(10,000$ NOK $)$ & 0.0000 & -0.384 & 0.0000 & -0.327 & 0.0001 & 2.081 & 0.0000 & -0.157 \\
\hline Benefit receiver ( $1=$ yes) & 0.0115 & 3.513 & 0.0034 & 1.945 & 0.0011 & 0.570 & -0.0160 & -3.794 \\
\hline \multicolumn{9}{|l|}{ Industries } \\
\hline Agricult.+ Fisheries & -0.0231 & -2.594 & -0.0121 & -2.464 & -0.0053 & -0.736 & 0.0404 & 3.243 \\
\hline Private services & -0.0106 & -3.352 & -0.0057 & -3.784 & -0.0063 & -2.519 & 0.0227 & 5.281 \\
\hline Transport and commu. & -0.0167 & -4.509 & -0.0145 & -5.449 & 0.0118 & 6.607 & 0.0194 & 3.993 \\
\hline Real estate + Finance & -0.0057 & -1.246 & -0.0083 & -3.511 & 0.0038 & 1.473 & 0.0102 & 1.773 \\
\hline Education + Health & -0.0147 & -5.198 & -0.0136 & -6.884 & 0.0025 & 1.501 & 0.0258 & 6.762 \\
\hline \multicolumn{9}{|l|}{ Year dummies } \\
\hline 1990 & 0.0032 & 0.873 & -0.0050 & -2.342 & -0.0012 & -0.340 & 0.0030 & 0.554 \\
\hline 1991 & 0.0052 & 1.241 & 0.0022 & 1.051 & 0.0008 & 0.194 & -0.0082 & -1.351 \\
\hline 1992 & 0.0160 & 3.306 & 0.0092 & 3.731 & 0.0044 & 0.958 & -0.0295 & -4.168 \\
\hline 1993 & 0.0084 & 1.429 & 0.0116 & 3.994 & 0.0040 & 0.712 & -0.0240 & -2.792 \\
\hline 1994 & 0.0208 & 3.116 & 0.0115 & 3.411 & 0.0129 & 1.985 & -0.0452 & -4.552 \\
\hline 1995 & 0.0072 & 0.921 & 0.0097 & 2.509 & 0.0058 & 0.762 & -0.0227 & -1.953 \\
\hline \multicolumn{9}{|l|}{ Local municipality } \\
\hline Residence density & 0.0006 & 1.277 & -0.0003 & -1.183 & -0.0008 & -2.725 & 0.0005 & 0.817 \\
\hline Distance to center & -0.0003 & -0.627 & -0.0001 & -0.577 & 0.0012 & 3.371 & -0.0007 & -1.009 \\
\hline Unemployment rate & 0.1860 & 3.219 & 0.1728 & 5.635 & -0.0396 & -1.047 & -0.3192 & -4.219 \\
\hline Constant & -0.2433 & -6.201 & -0.0873 & -4.283 & -0.4327 & -13.073 & 0.7633 & 13.852 \\
\hline Nbr. of observations & 1314 & & 869 & & 897 & & 26082 & \\
\hline Pseudo R2 & & & & & & & & \\
\hline Log Likelihood & -11841.6 & & & & & & & \\
\hline
\end{tabular}


Table 5. Exit probabilities (percentage). Original, and predicted with the opposite gender's vector of coefficients

\begin{tabular}{|lcccrcr|}
\hline & \multicolumn{3}{c}{ Females } & \multicolumn{5}{c|}{ Males } \\
\hline States & Original & $\begin{array}{c}\text { w/male } \\
\text { coeff's }\end{array}$ & Diff. & Original & $\begin{array}{c}\text { w/female } \\
\text { coeff's }\end{array}$ & Diff. \\
\hline Work & 90.5 & 82.0 & -8.5 & 89.4 & 89.9 & 0.5 \\
\hline Disability & 4.8 & 11.0 & 6.2 & 4.5 & 5.5 & 1.0 \\
\hline Unempl. & 2.3 & 4.9 & 2.6 & 3.0 & 2.6 & -0.3 \\
\hline Out of lab. & 2.4 & 2.1 & -0.3 & 3.1 & 2.0 & -1.1 \\
\hline
\end{tabular}

